\title{
Corrigendum
}

\section{Tensile and hydraulic properties of geosynthetics after mechanical damage and abrasion laboratory tests}

\author{
A. Rosete, P. Mendonça Lopes, M. Pinho-Lopes and M. L. Lopes \\ REFERENCE: Rosete, A., Mendonça Lopes, P., Pinho-Lopes, M. \& Lopes, M. L. (2013). Tensile and \\ hydraulic properties of geosynthetics after mechanical damage and abrasion laboratory tests. \\ Geosynthetics International, 20, No. 5, 358-374. [http://dx.doi.org/10.1680/gien.13.00022]
}

In Table 1 'Woven PP geotextile' should read 'Nonwoven PP geotextile'. In the first line of the left-hand column on page 364 , 'by normal distribution functions' should read 'by $t$-Student distribution functions'.

The authors apologise for these typographical errors. 